Pacific Journal of Mathematics

OSCILLATION CRITERIA FOR GENERAL LINEAR ORDINARY 


\section{OSCILLATION CRITERIA FOR GENERAL LINEAR ORDINARY DIFFERENTIAL EQUATIONS}

\section{Takaŝi Kunano and Manabu Naito}

\section{Lovelady has recently proved the following oscillation theorem.}

Theorem. Let $n \geqq 4$ be even and $q:[a, \infty) \rightarrow(0, \infty)$ be continuous. If $\int^{\infty} t^{n-2} q(t) d t<\infty$ and the second order equation

$$
\frac{d^{2} z}{d t^{2}}+\left(\frac{1}{(n-3) !} \int_{t}^{\infty}(s-t)^{n-3} q(s) d s\right) z=0
$$

is oscillatory, then the $n$th order equation

$$
x^{(n)}+q(t) x=0
$$

is oscillatory.

In this paper the above theorem will be extended to a class of differential equations of the form

$$
\frac{1}{p_{n}(t)} \frac{d}{d t} \frac{1}{p_{n-1}(t)} \frac{d}{d t} \cdots \frac{d}{d t} \frac{1}{p_{1}(t)} \frac{d}{d t} \frac{x}{p_{0}(t)}+q(t) x=0 .
$$

Let $n \geqq 4$ be an even number, let $p_{i}, 0 \leqq i \leqq n$, and $q$ be positive continuous functions on $[a, \infty)$, and consider the linear differential equation

$$
L_{n} x+q(t) x=0,
$$

where $L_{n}$ denotes the general disconjugate operator

$$
L_{n}=\frac{1}{p_{n}(t)} \frac{d}{d t} \frac{1}{p_{n-1}(t)} \frac{d}{d t} \cdots \frac{d}{d t} \frac{1}{p_{1}(t)} \frac{d}{d t} \frac{.}{p_{0}(t)} .
$$

We introduce the notation:

$$
D^{0}\left(x ; p_{0}\right)(t)=\frac{x(t)}{p_{0}(t)},
$$

$$
D^{j}\left(x ; p_{0}, \cdots, p_{j}\right)(t)=\frac{1}{p_{j}(t)} \frac{d}{d t} D^{j-1}\left(x ; p_{0}, \cdots, p_{j-1}\right)(t),
$$

$$
1 \leqq j \leqq n
$$

The differential operator $L_{n}$ defined by (2) can then be rewritten as

$$
L_{n}=D^{n}\left(\cdot ; p_{0}, \cdots, p_{n}\right) \text {. }
$$

The domain $\mathscr{D}\left(L_{n}\right)$ of $L_{n}$ is defined to be the set of all functions $x:[a, \infty) \rightarrow R$ such that $D^{j}\left(x ; p_{0}, \cdots, p_{j}\right)(t), 0 \leqq j \leqq n$, exist and are continuous on $[a, \infty)$. By a solution of equation (1) we mean a func- 
tion $x \in \mathscr{D}\left(L_{n}\right)$ which satisfies (1) on $[a, \infty)$. A nontrivial solution of (1) is called oscillatory if the set of its zeros is unbounded, and it is called nonoscillatory otherwise. Equation (1) itself is said to be oscillatory if all of its nontrivial solutions are oscillatory.

The study of the oscillatory behavior of higher-order ordinary differential equations goes back to Kneser [12] and has received a great deal of attention up to the present. For typical results on the subject we refer to the papers $[1,2,4-6,8,10,11,13,14,16,18]$.

In what follows we are primarily interested in the situation in which equation (1) is oscillatory. We have been motivated by the observation that there are very few effective criteria for equation (1) with general $L_{n}$ to be oscillatory, though equation (1) and its nonlinear analogue have been the object of intensive investigations in recent years. The desired oscillation criterion is established in $\S 2$. It generalizes an interesting oscillation theorem of Lovelady [15] for the particular equation $x^{(n)}+q(t) x=0$.

1. Preliminaries. We begin by formulating preparatory results which are needed in proving the main theorem in the next section.

Let $i_{k} \in\{1, \cdots, n-1\}, 1 \leqq k \leqq n-1$, and $t, s \in[a, \infty)$. Generalizing upon notation introduced by Willett [19], we define

$$
\begin{aligned}
& I_{0}=1, \\
& I_{k}\left(t, s ; p_{i_{k}}, \cdots, p_{i_{1}}\right)=\int_{s}^{t} p_{i_{k}}(u) I_{k-1}\left(u, s ; p_{i_{k-1}}, \cdots, p_{i_{1}}\right) d u .
\end{aligned}
$$

It is easy to verify that for $1 \leqq k \leqq n-1$

$$
\begin{gathered}
I_{k}\left(t, s ; p_{i_{k}}, \cdots, p_{i_{1}}\right)=(-1)^{k} I_{k}\left(s, t ; p_{i_{1}}, \cdots, p_{i_{k}}\right), \\
I_{k}\left(t, s ; p_{i_{k}}, \cdots, p_{i_{1}}\right)=\int_{s}^{t} p_{i_{1}}(u) I_{k-1}\left(t, u ; p_{i_{k}}, \cdots, p_{i_{2}}\right) d u .
\end{gathered}
$$

For convenience of notation we put

$$
\begin{array}{cc}
J_{i}(t, s)=p_{0}(t) I_{i}\left(t, s ; p_{1}, \cdots, p_{i}\right), & J_{i}(t)=J_{i}(t, a), \\
K_{i}(t, s)=p_{n}(t) I_{i}\left(t, s ; p_{n-1}, \cdots, p_{n-i}\right), & K_{i}(t)=K_{i}(t, a) .
\end{array}
$$

Lemma 1. If $x \in \mathscr{D}\left(L_{n}\right)$, then for $t, s \in[a, \infty)$ and $0 \leqq i<k \leqq n-1$

$$
\begin{aligned}
D^{i}\left(x ; p_{0}, \cdots, p_{i}\right)(t)-D^{i}\left(x ; p_{0}, \cdots, p_{i}\right)(s) \\
=\sum_{j=i+1}^{k}(-1)^{j-i} D^{j}\left(x ; p_{0}, \cdots, p_{j}\right)(s) I_{j-i}\left(s, t ; p_{j}, \cdots, p_{i+1}\right) \\
\quad+(-1)^{k-i+1} \int_{t}^{s} I_{k-i}\left(u, t ; p_{k}, \cdots, p_{i+1}\right) p_{k+1}(u) \\
\quad \times D^{k+1}\left(x ; p_{0}, \cdots, p_{k+1}\right)(u) d u .
\end{aligned}
$$


This lemma is a generalization of Taylor's formula with remainder encountered in calculus. The proof is immediate.

LEMMA 2. If there exists an eventually positive function $y \in$ $\mathscr{D}\left(L_{n}\right)$ satisfying

$$
L_{n} y+q(t) y \leqq 0
$$

for all large $t$, then equation (1) has an eventually positive solution.

This lemma exhibits an important relationship between the differential equation (1) and the differential inequality (10). For the proof see Čanturija [3].

In what follows we assume that

$$
\int_{a}^{\infty} p_{i}(t) d t=\infty \quad \text { for } \quad 1 \leqq i \leqq n-1 .
$$

The operator $L_{n}$ satisfying condition (11) is said to be in canonical form. It is known that any operator $L_{n}$ of the form (2) can always be represented in canonical form in an essentially unique way (see Trench [17]).

Lemma 3. Suppose (11) holds. If $x \in \mathscr{D}\left(L_{n}\right)$ satisfies $x(t) L_{n} x(t)<0$ on $\left[t_{0}, \infty\right)$, then there exist an odd integer $l, 1 \leqq l \leqq n-1$, and $a$ $t_{1}>t_{0}$ such that

$$
\begin{aligned}
& x(t) D^{j}\left(x ; p_{0}, \cdots, p_{j}\right)(t)>0 \text { on }\left[t_{1}, \infty\right) \text { for } 0 \leqq j \leqq l \text {, } \\
& (-1)^{j-l} x(t) D^{j}\left(x ; p_{0}, \cdots, p_{j}\right)(t)>0 \text { on }\left[t_{1}, \infty\right) \\
& \text { for } l+1 \leqq j \leqq n .
\end{aligned}
$$

This lemma generalizes a well-known lemma of Kiguradze [9] and can be proved similarly.

2. Main Result. The best oscillation theorem known to date for equation (1) is the following theorem due to Trench [18].

THEOREM A. Suppose (11) holds. If

$$
\int^{\infty} J_{i-1}(t) K_{n-i-1}(t) q(t) d t=\infty \quad \text { for } \quad i=1,3, \cdots, n-1,
$$

then equation (1) is oscillatory.

A question naturally arises as to what will happen when condition (14) is violated. In fact, Theorem A cannot cover an important class of Euler's equations of the form 


$$
\frac{d^{m}}{d t^{m}} t^{\alpha+m} \frac{d^{m} x}{d t^{m}}+c t^{\alpha-m} x=0, \quad t \geqq 1,
$$

where $\alpha$ and $c>0$ are constants with $\alpha+m \leqq 1$, since in this case the integrals appearing in (14) converge.

An answer to this question is given in the following theorem, which reduces the oscillation of equation (1) to the oscillation of a certain set of second order linear differential equations.

Theorem B. Suppose $n \geqq 4$, (11) holds, and the integrals in (14) converge. Define

$$
\begin{array}{r}
q_{i}(t)=p_{\imath+1}(t) \int_{t}^{\infty} J_{i-1}(u, t) K_{n-i-2}(u, t) q(u) d u, \\
i=1,3, \cdots, n-3 ; \\
q_{n-1}(t)=p_{n-2}(t) \int_{t}^{\infty} J_{n-3}(u, t) K_{0}(u, t) q(u) d u .
\end{array}
$$

Then equation (1) is oscillatory if the second order equations

$$
\frac{d}{d t} \frac{1}{p_{i}(t)} \frac{d z}{d t}+q_{i}(t) z=0, \quad i=1,3, \cdots, n-1,
$$

are oscillatory.

Proof. Suppose $x(t)$ is a nonoscillatory solution of (1). We may suppose $x(t)$ is eventually positive. Let $t_{0} \geqq a$ be such that $x(t)>0$ for $t \geqq t_{0}$. Lemma 3 implies that there exists an odd integer $l$, $1 \leqq l \leqq n-1$, such that (12) and (13) hold for $t \geqq t_{1}$, provided $t_{1}>t_{0}$ is sufficiently large.

Suppose $1 \leqq l \leqq n-3$. Then, from Lemma 1 applied to $x(t)$ with $i=l+1, k=n-1$ and $s \geqq t \geqq t_{1}$ it follows that

$$
\begin{aligned}
& D^{l+1}\left(x ; p_{0}, \cdots, p_{l+1}\right)(t)-D^{l+1}\left(x ; p_{0}, \cdots, p_{l+1}\right)(s) \\
& \quad=\sum_{j=l+2}^{n-1}(-1)^{j-l-1} D^{j}\left(x ; p_{0}, \cdots, p_{j}\right)(s) I_{j-l-1}\left(s, t ; p_{j}, \cdots, p_{l+2}\right) \\
& \quad+(-1)^{n-l-1} \int_{t}^{s} I_{n-l-2}\left(u, t ; p_{n-1}, \cdots, p_{l+2}\right) p_{n}(u) D^{n}\left(x ; p_{0}, \cdots, p_{n}\right)(u) d u .
\end{aligned}
$$

Using (12) and (13) in the above and letting $s \rightarrow \infty$, we have

$$
\begin{aligned}
& -D^{l+1}\left(x ; p_{0}, \cdots, p_{l+1}\right)(t) \\
& \quad \geqq \int_{t}^{\infty} p_{n}(u) I_{n-l-2}\left(u, t ; p_{n-1}, \cdots, p_{l+2}\right) q(u) x(u) d u
\end{aligned}
$$

for $t \geqq t_{1}$. If $l \geqq 3$, then using Lemma 1 again (with $i=0, k=l-2$, $s=t_{1}$ and $\left.t \geqq t_{1}\right)$ and (5), we get 


$$
\begin{aligned}
D^{0}(x ; & \left.p_{0}\right)(t)-D^{0}\left(x ; p_{0}\right)\left(t_{1}\right) \\
= & \sum_{j=1}^{l-2}(-1)^{j} D^{j}\left(x ; p_{0}, \cdots, p_{j}\right)\left(t_{1}\right) I_{j}\left(t_{1}, t ; p_{j}, \cdots, p_{1}\right) \\
& \quad+(-1)^{l-1} \int_{t}^{t_{1}} I_{l-2}\left(u, t ; p_{l-2}, \cdots, p_{1}\right) p_{l-1}(u) D^{l-1}\left(x ; p_{0}, \cdots, p_{l-1}\right)(u) d u \\
= & \sum_{j=1}^{l-2} D^{j}\left(x ; p_{0}, \cdots, p_{j}\right)\left(t_{1}\right) I_{j}\left(t, t_{1} ; p_{1}, \cdots, p_{j}\right) \\
& \quad+\int_{t}^{t_{1}} I_{l-2}\left(u, t ; p_{l-2}, \cdots, p_{1}\right) p_{l-1}(u) D^{l-1}\left(x ; p_{0}, \cdots, p_{l-1}\right)(u) d u .
\end{aligned}
$$

Thus in view of (12) we obtain

(20) $\quad D^{0}\left(x ; p_{0}\right)(t) \geqq \int_{t_{1}}^{t} I_{l-2}\left(t, u ; p_{1}, \cdots, p_{l-2}\right) p_{l-1}(u) D^{l-1}\left(x ; p_{0}, \cdots, p_{l-1}\right)(u) d u$ for $t \geqq t_{1}$. Combining (19) with (20) yields

$$
\begin{aligned}
& -D^{l+1}\left(x ; p_{0}, \cdots, p_{l+1}\right)(t) \\
& \geqq \int_{t}^{\infty} p_{n}(u) I_{n-l-2}\left(u, t ; p_{n-1}, \cdots, p_{l+2}\right) q(u) p_{0}(u) \\
& \quad \times \int_{t_{1}}^{u} I_{l-2}\left(u, v ; p_{1}, \cdots, p_{l-2}\right) p_{l-1}(v) D^{l-1}\left(x ; p_{0}, \cdots, p_{l-1}\right)(v) d v d u \\
& \geqq \int_{t}^{\infty} p_{n}(u) I_{n-l-2}\left(u, t ; p_{n-1}, \cdots, p_{l+2}\right) q(u) p_{0}(u) \\
& \quad \times \int_{t}^{u} I_{l-2}\left(u, v ; p_{1}, \cdots, p_{l-2}\right) p_{l-1}(v) D^{l-1}\left(x ; p_{0}, \cdots, p_{l-1}\right)(v) d v d u
\end{aligned}
$$

for $t \geqq t_{1}$. Since $D^{l-1}\left(x ; p_{0}, \cdots, p_{l-1}\right)$ is increasing, we conclude from the above that

$$
\begin{aligned}
&-D^{l+1}\left(x ; p_{0}, \cdots, p_{l+1}\right)(t) \\
& \geqq D^{l-1}\left(x ; p_{0}, \cdots, p_{l-1}\right)(t) \int_{t}^{\infty} p_{n}(u) I_{n-l-2}\left(u, t ; p_{n-1}, \cdots, p_{l+2}\right) \\
& \quad \times q(u) p_{0}(u) \int_{t}^{u} I_{l-2}\left(u, v ; p_{1}, \cdots, p_{l-2}\right) p_{l-1}(v) d v d u \\
&= D^{l-1}\left(x ; p_{0}, \cdots, p_{l-1}\right)(t) \int_{t}^{\infty} p_{n}(u) I_{n-l-2}\left(u, t ; p_{n-1}, \cdots, p_{l+2}\right) \\
& \times q(u) p_{0}(u) I_{l-1}\left(u, t ; p_{1}, \cdots, p_{l-1}\right) d u,
\end{aligned}
$$

where we have used formula (6). Let $y(t)$ be given by

$$
y(t)=D^{l-1}\left(x ; p_{0}, \cdots, p_{l-1}\right)(t) .
$$

Note that $y(t)>0$ and in view of $(21)$

$$
-D^{l+1}\left(x ; p_{0}, \cdots, p_{l+1}\right)(t) \geqq y(t) \int_{t}^{\infty} K_{n-l-2}(u, t) J_{l-1}(u, t) q(u) d u
$$


for $3 \leqq l<n-1$ and $t \geqq t_{1}$. That (22) is true for $l=1$ follows immediately from (19). Since $d y(t) / d t=p_{l}(t) D^{l}\left(x ; p_{0}, \cdots, p_{l}\right)(t)$, we have

$$
\frac{d}{d t} \frac{1}{p_{l}(t)} \frac{d y(t)}{d t}=p_{l+1}(t) D^{l+1}\left(x ; p_{0}, \cdots, p_{l+1}\right)(t),
$$

which together with (22) implies

$$
\frac{d}{d t} \frac{1}{p_{l}(t)} \frac{d y(t)}{d t}+q_{l}(t) y(t) \leqq 0,
$$

where $q_{l}(t)$ is defined by (16). Now from Lemma 2 it follows that the equation

$$
\frac{d}{d t} \frac{1}{p_{l}(t)} \frac{d z}{d t}+q_{l}(t) z=0
$$

has a nonoscillatory solution. But this is impossible by hypothesis. Finally, suppose $l=n-1$. Integrating (1), we have

$$
D^{n-1}\left(x ; p_{0}, \cdots, p_{n-1}\right)(t) \geqq \int_{t}^{\infty} p_{n}(u) q(u) x(u) d u, \quad t \geqq t_{1} .
$$

On the other hand, application of Lemma 1 to the case where $i=0$, $k=n-3, s=t_{1}$ and $t \geqq t_{1}$ shows that

$$
\begin{aligned}
D^{0}(x ; & \left.p_{0}\right)(t)-D^{0}\left(x ; p_{0}\right)\left(t_{1}\right) \\
= & \sum_{j=1}^{n-3}(-1)^{j} D^{j}\left(x ; p_{0}, \cdots, p_{j}\right)\left(t_{1}\right) I_{j}\left(t_{1}, t ; p_{j}, \cdots, p_{1}\right) \\
& +(-1)^{n-2} \int_{t}^{t_{1}} I_{n-3}\left(u, t ; p_{n-3}, \cdots, p_{1}\right) p_{n-2}(u) D^{n-2}\left(x ; p_{0}, \cdots, p_{n-2}\right)(u) d u \\
= & \sum_{j=1}^{n-3} D^{j}\left(x ; p_{0}, \cdots, p_{j}\right)\left(t_{1}\right) I_{j}\left(t, t_{1} ; p_{1}, \cdots, p_{j}\right) \\
& +\int_{t_{1}}^{t} I_{n-3}\left(t, u ; p_{1}, \cdots, p_{n-3}\right) p_{n-2}(u) D^{n-2}\left(x ; p_{0}, \cdots, p_{n-2}\right)(u) d u .
\end{aligned}
$$

This implies that

$$
\begin{aligned}
& D^{0}\left(x ; p_{0}\right)(t) \\
& \quad \geqq \int_{t_{1}}^{t} I_{n-3}\left(t, u ; p_{1}, \cdots, p_{n-3}\right) p_{n-2}(u) D^{n-2}\left(x ; p_{0}, \cdots, p_{n-2}\right)(u) d u
\end{aligned}
$$

for $t \geqq t_{1}$. From (23) and (24) we obtain

$$
\begin{aligned}
& D^{n-1}\left(x ; p_{0}, \cdots, p_{n-1}\right)(t) \\
& \geqq \int_{t}^{\infty} p_{n}(u) q(u) p_{0}(u) \int_{t_{1}}^{u} I_{n-3}\left(u, v ; p_{1}, \cdots, p_{n-3}\right) p_{n-2}(v) \\
& \quad \times D^{n-2}\left(x ; p_{0}, \cdots, p_{n-2}\right)(v) d v d u
\end{aligned}
$$




$$
\begin{aligned}
\geqq & \int_{t}^{\infty} p_{n}(u) q(u) p_{0}(u) \int_{t}^{u} I_{n-3}\left(u, v ; p_{1}, \cdots, p_{n-3}\right) p_{n-2}(v) \\
& \times D^{n-2}\left(x ; p_{0}, \cdots, p_{n-2}\right)(v) d v d u \\
= & \int_{t}^{\infty}\left(\int_{v}^{\infty} p_{n}(u) p_{0}(u) I_{n-3}\left(u, v ; p_{1}, \cdots, p_{n-3}\right) q(u) d u\right) p_{n-2}(v) \\
& \times D^{n-2}\left(x ; p_{0}, \cdots, p_{n-2}\right)(v) d v .
\end{aligned}
$$

It follows that for $t \geqq t_{1}$

$$
\begin{aligned}
& D^{n-1}\left(x ; p_{0}, \cdots, p_{n-1}\right)(t) \\
& \quad \geqq \int_{t}^{\infty}\left(\int_{v}^{\infty} J_{n-3}(u, v) K_{0}(u, v) q(u) d u\right) p_{n-2}(v) D^{n-2}\left(x ; p_{0}, \cdots, p_{n-2}\right)(v) d v .
\end{aligned}
$$

Integrating the above inequality from $t_{1}$ to $t$, we see that the positive function $w(t)=D^{n-2}\left(x ; p_{0}, \cdots, p_{n-2}\right)(t)$ satisfies

$$
w(t) \geqq w\left(t_{1}\right)+\int_{t_{1}}^{t} p_{n_{-1}}(u) \int_{u}^{\infty} q_{n-1}(v) w(v) d v d u
$$

for $t \geqq t_{1}$, where $q_{n-1}(t)$ is given by (17). Denote the right hand side of (25) by $y(t)$. By differentiation

$$
\frac{d}{d t} \frac{1}{p_{n-1}(t)} \frac{d y(t)}{d t}+q_{n-1}(t) w(t)=0, \quad t \geqq t_{1},
$$

and so

$$
\frac{d}{d t} \frac{1}{p_{n-1}(t)} \frac{d y(t)}{d t}+q_{n-1}(t) y(t) \leqq 0, \quad t \geqq t_{1} .
$$

Again by Lemma 2 we see that the equation

$$
\frac{d}{d t} \frac{1}{p_{n-1}(t)} \frac{d z}{d t}+q_{n-1}(t) z=0
$$

has a nonoscillatory solution, contradicting the hypothesis. This completes the proof in the case $l=n-1$.

REMARK. According to a classical oscillation criterion of Hille [7] equations (18) are oscillatory if

$$
\liminf _{t \rightarrow \infty} \int_{a}^{t} p_{i}(s) d s \cdot \int_{t}^{\infty} q_{i}(s) d s>\frac{1}{4}, \quad i=1,3, \cdots, n-1 .
$$

It is not difficult to see that, when specialized to the particular equation

$$
\frac{d^{m}}{d t^{m}} \frac{1}{p_{m}(t)} \frac{d^{m} x}{d t^{m}}+q(t) x=0
$$


Theorem $\mathrm{B}$ yields the following result which contains the theorem of Lovelady stated at the beginning of this paper. that:

CoROllary. Suppose that $\int^{\infty} p_{m}(t) d t=\infty$. Suppose moreover

(i) if $m=2$, then the equation

$$
\frac{d^{2} z}{d t^{2}}+\left(p_{m}(t) \int_{t}^{\infty}(u-t) q(u) d u\right) z=0
$$

is oscillatory;

(ii) if $m>2$ is even, then the equations

$$
\begin{aligned}
\frac{d^{2} z}{d t^{2}}+ & \left(\frac{1}{(m-1) !(m-3) !}\right. \\
& \left.\times \int_{t}^{\infty}\left(\int_{t}^{u}(u-v)^{m-1}(v-t)^{m-3} p_{m}(v) d v\right) q(u) d u\right) z=0,
\end{aligned}
$$

$$
\frac{d^{2} z}{d t^{2}}+\left(\frac{p_{m}(t)}{(m-1) !(m-2) !} \int_{t}^{\infty}(u-t)^{2 m-3} q(u) d u\right) z=0
$$

are oscillatory; and

(iii) if $m>2$ is odd, then the equations (29) and

$$
\frac{d}{d t} \frac{1}{p_{m}(t)} \frac{d z}{d t}+\left(\frac{1}{(m-1) !(m-2) !} \int_{t}^{\infty}(u-t)^{2 m-3} q(u) d u\right) z=0
$$

are oscillatory. Then equation (27) is oscillatory.

ExAmple. Consider the Euler equation

$$
\frac{d^{m}}{d t^{m}} t^{\alpha+m} \frac{d^{m} x}{d t^{m}}+c t^{\alpha-m} x=0, \quad t \geqq 1,
$$

where $\alpha$ and $c>0$ are real constants, and $\alpha \leqq-m+1$.

It is a matter of easy computation to find that the second order equations (28), (29), (30), and (31) associated with (15) reduce respectively to

$$
\begin{aligned}
& \frac{d^{2} z}{d t^{2}}+\frac{c}{\alpha(\alpha-1) t^{2}} z=0, \\
& \frac{d^{2} z}{d t^{2}}+\frac{c}{(m-1) ! \alpha(\alpha-1) \cdots(\alpha-m+1) t^{2}} z=0, \\
& \frac{d^{2} z}{d t^{2}}+\frac{(2 m-3) ! c}{(m-1) !(m-2) !(\alpha+m-2)(\alpha+m-3) \cdots(\alpha-m+1) t^{2}} z=0,
\end{aligned}
$$

and 


$$
\frac{d}{d t} t^{\alpha+m} \frac{d z}{d t}+\frac{(2 m-3) ! c t^{\alpha+m-2}}{(m-1) !(m-2) !(\alpha+m-2)(\alpha+m-3) \cdots(\alpha-m+1)} z=0 .
$$

Note that these are Euler equations of the second order. Consequently, we conclude that equation (15) is oscillatory provided $c$ is so large that

(i) when $m=2, c>(1 / 4) \alpha(\alpha-1)$;

(ii) when $m>2$ is even,

$$
\begin{aligned}
c> & \frac{1}{4} \max \{(m-1) ! \alpha(\alpha-1) \cdots(\alpha-m+1), \\
& \left.\frac{(m-1) !(m-2) !}{(2 m-3) !}(\alpha+m-2)(\alpha+m-3) \cdots(\alpha-m+1)\right\} ;
\end{aligned}
$$

(iii) when $m>2$ is odd,

$$
\begin{aligned}
c> & \frac{1}{4} \max \{(m-1) ! \alpha(\alpha-1) \cdots(\alpha-m+1), \\
& \left.\frac{(m-1) !(m-2) !}{(2 m-3) !}(\alpha+m-1)^{2}(\alpha+m-2)(\alpha+m-3) \cdots(\alpha-m+1)\right\} .
\end{aligned}
$$

Let us now turn to the case where $\alpha>-m+1$. To examine this case we consider the fourth order equation

$$
\frac{d^{2}}{d t^{2}} t^{\alpha+2} \frac{d^{2} x}{d t^{2}}+c t^{\alpha-2} x=0, \quad t \geqq 1,
$$

where we suppose that $\alpha>-1$. We observe that the differential operator $\left(d^{2} / d t^{2}\right) t^{\alpha+2}\left(d^{2} / d t^{2}\right)$ can be represented in canonical form as follows:

$$
\begin{array}{cc}
\frac{d}{d t} t^{\alpha+1} \frac{d}{d t} t^{-\alpha} \frac{d}{d t} t^{\alpha+1} \frac{d}{d t} & (-1<\alpha \leqq 0), \\
t^{\alpha} \frac{d}{d t} t^{1-\alpha} \frac{d}{d t} t^{\alpha} \frac{d}{d t} t^{1-\alpha} \frac{d}{d t} t^{\alpha} & (0<\alpha<1), \\
t^{\alpha} \frac{d^{2}}{d t^{2}} t^{2-\alpha} \frac{d^{2}}{d t^{2}} t^{\alpha} \quad(\alpha \geqq 1) .
\end{array}
$$

Let $0<\alpha<1$, for example. Then in view of (34) equation (32) is equivalent to

$$
\frac{d}{d t} t^{1-\alpha} \frac{d}{d t} t^{\alpha} \frac{d}{d t} t^{1-\alpha} \frac{d y}{d t}+c t^{-\alpha-2} y=0
$$

and, as easily cheked, the second order equations (18) associated with (36) reduce to the single equation 


$$
\frac{d}{d t} t^{1-\alpha} \frac{d z}{d t}+\frac{c}{\alpha+1} t^{-\alpha-1} z=0
$$

which is an Euler equation of the second order. From the remark following the proof of Theorem B equation (37) is oscillatory if

$$
\liminf _{t \rightarrow \infty} \int_{1}^{t} s^{\alpha-1} d s \cdot \int_{t}^{\infty} \frac{c}{\alpha+1} s^{-\alpha-1} d s=\frac{c}{\alpha^{2}(\alpha+1)}>\frac{1}{4} .
$$

Thus, in case $0<\alpha<1$, equation (32) is oscillatory if $c>\alpha^{2}(\alpha+1) / 4$. Similarly, it can be shown that (32) is oscillatory if $c>\alpha^{2}(1-\alpha) / 4$ in case $-1<\alpha \leqq 0$ and if $c>\alpha(\alpha+1) / 4$ in case $\alpha \geqq 1$. It follows that equation (32) is oscillatory for every $\alpha$ provided $c$ is sufficiently large.

The canonical representation of the operator $\left(d^{m} / d t^{m}\right) t^{\alpha+m}\left(d^{m} / d t^{m}\right)$ with general $m>2$ and $\alpha>-m+1$ is not known to us.

ACKNowledgment. The authors would like to express their sincere gratitude to the referee for his very helpful comments and suggestions.

\section{REFERENCES}

1. G. V. Anan'eva and V. I. Balaganskii, Oscillation of the solutions of certain differ. ential equations of high order, Uspehi Mat. Nauk, 14, No. 1 (85) (1959), 135-140. (Russian) 2. G. A. Bogar, Oscillation properties of two term linear differential equations, Trans. Amer. Math. Soc., 161 (1971), 25-33.

3. T. A. Čanturija, Some comparison theorems for higher order ordinary differential equations, Bull. Acad. Polon. Sci. Ser. Sci. Math. Astronom. Phys., 25 (1977), 749-756. (Russian)

4. U. Elias, Nonoscillation and eventual disconjugacy, Proc. Amer. Math. Soc., 66 (1977), 269-275.

5. - Oscillatory solutions and extremal points for a linear differential equation, Arch. Rational Mech. Anal., 71 (1979), 177-198.

6. A. Granata, Singular Cauchy problems and asymptotic behavior for a class of nth order differential equations, Funkcial. Ekavac., 20 (1977), 193-212.

7. E. Hille, Non-oscillation theorems, Trans. Amer. Math. Soc., 64 (1948), 234-252.

8. A. G. Kartsatos, Oscillation properties of solutions of even order differential equations, Bull. Fac. Sci. Ibaraki Univ. Ser. A, 2 (1969), 9-14.

9. I. T. Kiguradze, On the oscillation of solutions of the equation $d^{m} u / d t^{m}+$ $a(t)|u|^{n} \operatorname{sign} u=0$, Mat. Sb., 65 (1964), 172-187. (Russian)

10. Y. Kitamura and T. Kusano, Oscillation criteria for semilinear metaharmonic equa. tions in exterior domains, Arch. Rational Mech. Anal., (to appear).

11. Nonlinear oscillation of higher-order functional differential equations with deviating arguments, J. Math. Anal. Appl., 77 (1980), 100-119.

12. A. Kneser, Untersuchungen über die reellen Nullstellen der Integrale linearer Differentialgleichungen, Math. Ann., 42 (1893), 409-435.

13. K. Kreith and T. Kusano, Extremal solutions of general nonlinear differential equa. tions, Hiroshima Math. J., 10 (1980), 141-152.

14. D. L. Lovelady, On the oscillatory behavior of bounded solutions of higher order differential equations, J. Differential Equations, 19 (1975), 167-175. 
15. D. L. Lovelady, Oscillation and even order linear differential equations, Rocky Mountain J. Math., 6 (1976), 299-304.

16. Z. Nehari, Non-oscillation criteria for nth order linear differential equations, Duke Math. J., 32 (1965), 607-615.

17. W. F. Trench, Canonical forms and principal systems for general disconjugate equa. tions, Trans. Amer. Math. Soc., 189 (1974), 319-327.

18. - Oscillation properties of perturbed disconjugate equations, Proc. Amer. Math. Soc., 52 (1975), 147-155.

19. D. Willett, Asymptotic behavior of disconjugate nth order differential equations, Canad. J. Math., 23 (1971), 293-314.

Received October 3, 1979.

Hiroshima University

HiRoshima, Japan 



\section{PACIFIC JOURNAL OF MATHEMATICS}

\section{EDITORS}

DONALD BABBITT (Managing Editor)

University of California

Los Angeles, CA 90024

HUGo RossI

University of Utah

Salt Lake City, UT 84112

C. C. MOORE and ANDREW OGG

University of California

Berkeley, CA 94720
J. DUGUNDJI

Department of Mathematics

University of Southern California

Los Angeles, CA 90007

R. FinN and J. Milgram

Stanford University

Stanford, CA 94305

\section{ASSOCIATE EDITORS}
R. ARENS
E. F. BECKENBACH
B. H. NeumanN
F. WOLF
K. Yoshida

\section{SUPPORTING INSTITUTIONS}

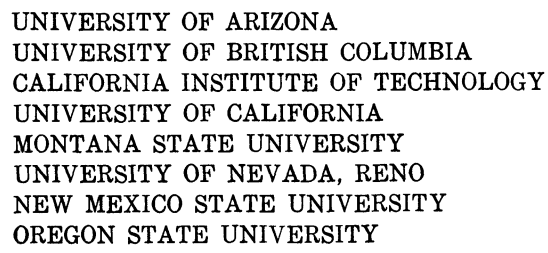

UNIVERSITY OF ARIZONA

UNIVERSITY OF BRITISH COLUMBIA CALIFORNIA INSTITUTE OF TECHNOLOGY

UNIVERSITY OF CALIFORNIA

MONTANA STATE UNIVERSITY

UNIVERSITY OF NEVADA, RENO

NEW MEXICO STATE UNIVERSITY

OREGON STATE UNIVERSITY

\author{
UNIVERSITY OF OREGON \\ UNIVERSITY OF SOUTHERN CALIFORNIA \\ STANFORD UNIVERSITY \\ UNIVERSITY OF HAWAII \\ UNIVERSITY OF TOKYO \\ UNIVERSITY OF UTAH \\ WASHINGTON STATE UNIVERSITY \\ UNIVERSITY OF WASHINGTON
}

The Supporting Institutions listed above contribute to the cost of publication of this Journal, but they are not owners or publishers and have no responsibility for its content or policies.

Mathematical papers intended for publication in the Pacific Journal of Mathematics should be in typed form or offset-reproduced, (not dittoed), double spaced with large margins. Please do not use built up fractions in the text of the manuscript. However, you may use them in the displayed equations. Underline Greek letters in red, German in green, and script in blue. The first paragraph or two must be capable of being used separately as a synopsis of the entire paper. Please propose a heading for the odd numbered pages of less than 35 characters. Manuscripts, in triplicate, may be sent to any one of the editors. Please classify according to the scheme of Math. Reviews, Index to Vol. 39. Supply name and address of author to whom proofs should be sent. All other communications should be addressed to the managing editor, or Elaine Barth, University of California, Los Angeles, California, 90024.

50 reprints to each author are provided free for each article, only if page charges have been substantially paid. Additional copies may be obtained at cost in multiples of 50 .

The Pacific Journal of Mathematics is issued monthly as of January 1966. Regular subscription rate: $\$ 102.00$ a year (6 Vols., 12 issues). Special rate: $\$ 51.00$ a year to individual members of supporting institutions.

Subscriptions, orders for numbers issued in the last three calendar years, and changes of address shoud be sent to Pacific Journal of Mathematics, P.O. Box 969, Carmel Valley, CA 93924, U.S.A Old back numbers obtainable from Kraus Periodicals Co., Route 100, Millwood, NY 10546.

\section{PUBLISHED BY PACIFIC JOURNAL OF MATHEMATICS, A NON-PROFIT CORPORATION}

Printed at Kokusai Bunken Insatsusha (International Academic Printing Co., Ltd.). 8-8, 3-chome, Takadanobaba, Shinjuku-ku, Tokyo 160, Japan. 


\section{Pacific Journal of Mathematics}

Vol. 92, No. $2 \quad$ February, 1981

Bruce Allem Anderson and Philip A. Leonard, Sequencings and Howell designs

Kevin T. Andrews, Representation of compact and weakly compact

operators on the space of Bochner integrable functions . . . . . . . . 257

James Glenn Brookshear, On the structure of hyper-real $z$-ultrafilters . . . . . 269

Frank John Forelli, Jr., A necessary condition on the extreme points of a class of holomorphic functions. II ...................... 277

Richard J. Friedlander, Basil Gordon and Peter Tannenbaum, Partitions of groups and complete mappings ......................... 283

Emden Robert Gansner, Matrix correspondences of plane partitions ......295

David Andrew Gay and William Yslas Vélez, The torsion group of a radical extension ..........................................

André (Piotrowsky) De Korvin and C. E. Roberts, Convergence theorems for some scalar valued integrals when the measure is Nemytskii ...... 329

Takaŝi Kusano and Manabu Naito, Oscillation criteria for general linear ordinary differential equations $\ldots \ldots \ldots \ldots \ldots \ldots \ldots \ldots \ldots \ldots \ldots \ldots \ldots \ldots \ldots \ldots$

Vo Thanh Liem, Homotopy dimension of some orbit spaces .......... 357

Mark Mahowald, $b o$-resolutions . . . . . . . . . . . . . . . . . . . 365

Jan van Mill and Marcel Lodewijk Johanna van de Vel, Subbases, convex

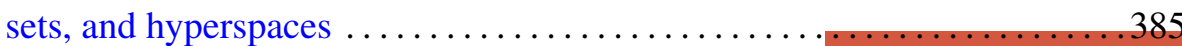

John F. Morrison, Approximations to real algebraic numbers by algebraic numbers of smaller degree $\ldots \ldots \ldots \ldots \ldots \ldots \ldots \ldots \ldots \ldots \ldots \ldots \ldots$

Caroline Series, An application of groupoid cohomology . . . . . . . . . . 415

Peter Frederick Stiller, Monodromy and invariants of elliptic surfaces . . . 433 Akihito Uchiyama, The factorization of $H^{p}$ on the space of homogeneous

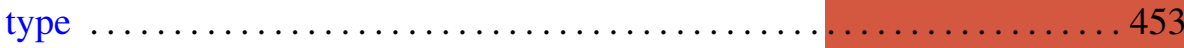

Warren James Wong, Maps on simple algebras preserving zero products.

II. Lie algebras of linear type 